\title{
Does the introduced polychaete Alitta succinea establish in the Caspian Sea?
}

\author{
Amir Faraz Ghasemi • Mehrshad Taheri • \\ Armin Jam
}

Received: 6 September 2012/Revised: 14 April 2013/Accepted: 16 April 2013/Published online: 25 April 2013

(c) Springer-Verlag Berlin Heidelberg and AWI 2013

\begin{abstract}
Members of the polychaete family Nereididae do not occur naturally in the Caspian Sea but are documented intentional human introductions that commenced in 1939. However, the identity of the species involved has been uncertain; material has been identified as both Alitta succinea and Hediste diversicolor. In this study, we confirm the presence of both species in the Caspian Sea. We discuss the distribution of both species, based on tolerance to physical factors, especially salinity. Although establishment of this partially predatory Nereidid, as a food reservoir could facilitate the recreation of commercially exploited fish stock, the consequences for native benthic communities are unclear and may be subject to unforeseen negative impacts.
\end{abstract}

Keywords Nereididae $\cdot$ Alitta succinea $\cdot$ Hediste diversicolor $\cdot$ Caspian Sea

Communicated by H.-D. Franke.

A. F. Ghasemi $(\bowtie) \cdot$ M. Taheri · A. Jam

Iranian National Institute for Oceanography, 9,

Etemadzadeh Avenue, West Fatemi Street, Tehran, Iran

e-mail: faraz_ghasemi@yahoo.com

A. F. Ghasemi

Faculty of Marine Science and Oceanography,

Khorramshahr University of Marine Science and Technology,

P.O. Box: 669, Khorramshahr, Khuzestan, Iran

M. Taheri

Department of Biology, Marine Biology Section, Ghent

University, Krijgslaan 281/S8, 9000 Ghent, Belgium

\section{Introduction}

Between 1939 and 1941, individual Nereididae worms were brought from the Sea of Azov into the Caspian Sea for acclimatization in order to increase the food resources for the commercial fish. Russian marine scientists introduced 6,100 specimens in different places of the Caspian Sea from the Sea of Azov (Zenkevitch et al. 1945). The northern Caspian was rapidly colonized, and the animals subsequently spread into the middle and southern parts of the sea. In autumn 1944, Nereididae worms were recorded for the first time in large quantities in the intestines of sturgeon from the Chechen Island (Spassky 1945). Initially, specialists thought the introduced species was Alitta succinea, but further examinations showed that the introduced species was Hediste diversicolor, and no specimen of A. succinea was recorded (Hartman 1960; Khlebovich 1963). Therefore, it was not clear whether A. succinea was established in the Caspian Sea or not Karpevich (1968, 1975), and most literature for the Caspian Sea has only reported $H$. diversicolor (Malinovskaja et al. 1998; Guseinov 2005; Karpinsky 2010; Roohi et al. 2010; Taheri and Foshtomi 2010; Taheri et al. 2011, 2012).

In 2010, during sampling of the macrobenthic community at shallow waters of the Mazandaran province, we observed some specimens with characteristics of $A$. succinea, especially based on paragnaths on region $\mathrm{V}$ of the eversible pharynx. This note confirms the presence of two introduced species, $H$. diversicolor and A. succinea, both occurring on soft substrates of shallow waters in the southern Caspian Sea. We will also discuss their life history and factors limiting the distributions of the species.

Both species are known under a variety of synonyms and have previously been referred to the genera Neanthes and Nereis. Here, we follow Bakken and Wilson (2005) and refer to them as A. succinea and $H$. diversicolor. 


\section{Materials and methods}

Study area

Mazandaran province is located in the middle of the southern beach of the Caspian Sea (Mazandaran Sea) along the Iranian coasts. There is almost no tidal range, and the gradient and structure of the seabed are uniform. The surface salinity and temperature to $20 \mathrm{~m}$ depth vary negligibly (Hadjizadeh Zaker et al. 2007). No major rivers exist in the vicinity of the sampling sites, but the most important phenomenon in these areas is strong rip currents (Shafiei Sabet and Barani 2011). Besides floating fishing nets are widely used annually from December to June.

Data collection

Seasonal sampling was conducted on the Noshahr coasts at 16 stations along four different depths $(2,5,9$, and $13 \mathrm{~m})$ within $51^{\circ} 31^{\prime} 11^{\prime \prime}$ to $51^{\circ} 49^{\prime} 06^{\prime \prime} \mathrm{E}$ and $36^{\circ} 35^{\prime} 10^{\prime \prime}$ to $36^{\circ} 39^{\prime} 55^{\prime \prime} \mathrm{N}$ (Fig. 1). At each station, three replicate samples were collected using a Van Veen grab with sampling area of $300 \mathrm{~cm}^{2}$. In the field, the content of each grab was stored in separate plastic containers. In the laboratory, each sample was gently sieved over $0.5-\mathrm{mm}$ mesh, and the retained material fixed in $4 \%$ buffered formalin and stained with Rose Bengal. One replicate sample from rocky substrate (1 m depth) was collected with scraping a surface of $225 \mathrm{~cm}^{2}(15 \mathrm{~cm} \times 15 \mathrm{~cm})$ and immediately thereafter washed through a $1-\mathrm{mm}$ mesh sieve, fixed in a $4 \%$ formalin solution, and preserved in $70 \%$ ethanol. Macrofauna were separated and all Nereididae identified and counted under a Olympus stereomicroscope and a Carl Zeiss Jena Laboval 4 microscope, and photographed with CCD and Nikon digital cameras. Another three replicate
Van Veen grab sediment samples were taken at each station for measuring percentage of total organic matter (TOM) and sediment grain size. Surface sediment ( $\approx 4 \mathrm{~cm}$ ) was subsampled and stored in a cleaned plastic container. The TOM was determined by weight loss on ignition $\left(4 \mathrm{~h}\right.$ at $\left.550{ }^{\circ} \mathrm{C}\right)$ after drying $\left(24 \mathrm{~h}\right.$ at $\left.90{ }^{\circ} \mathrm{C}\right)$ to constant weight (Abrantes et al. 1999). Grain size analysis was performed using a particle size analyzer. Sediment fractions (sand and silt-clay) were reported as percentage and defined according to the Wentworth scale. Physical data (temperature and salinity) of the water were recorded in two meter depth by the moored buoy of the Noshahr Ports and Maritime Organization. All data from the four stations at each depth (totaling 12 replicate samples from each depth) were plotted separately (Fig. 1).

\section{Results}

Averages of salinity, temperature, percentages of total organic matter (TOM), sand, silt-clay, and species density (ind $/ \mathrm{m}^{2}$ ) in the sampling months are given in Table 1. On soft substrates, 74 specimens of the two species were collected: Alitta succinea (42 specimens) and Hediste diversicolor (8 specimens). A further 24 damaged and juvenile specimens could not be identified (Table 2). A. succinea was collected at all depths in both soft and rocky substrates, while $H$. diversicolor was collected only along lines 3 and 4 in March and September, in an habitat characterized relatively greater depth and higher TOM and silt-clay.

On rocky substrates, only A. succinea was present (48 specimens), typically among Mytilaster lineatus, Balanus improvises, and Rhithropanopeus harrisii communities. In this area, we observed the highest density of $A$. succinea (more than 2,100 ind $/ \mathrm{m}^{2}$ ) with more numbers of fishing net
Fig. 1 Map of sampling area (left) and location of sampling stations in Mazandaran province with depth lines (line $1=2$, line $2=5$; line $3=9$ and line $4=13 \mathrm{~m}$ )

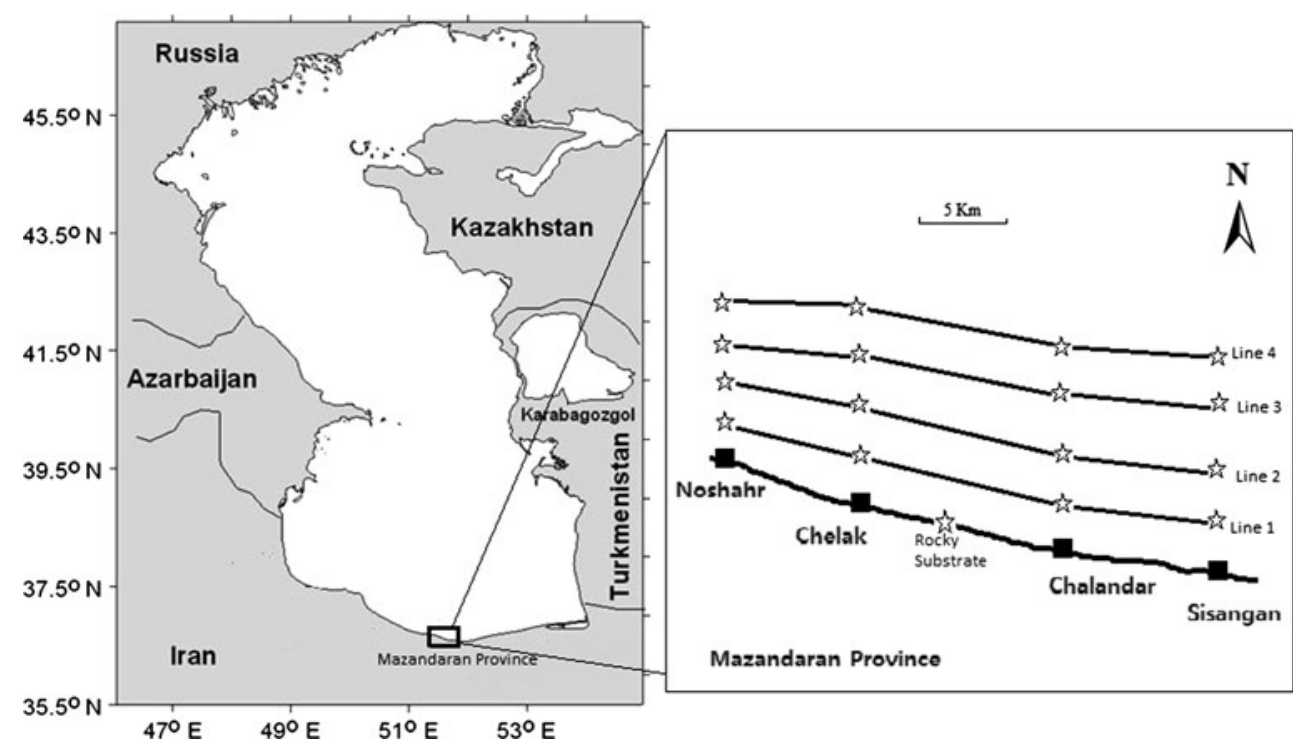


Table 1 Averages of salinity, temperature, percentages of total organic matter (TOM), sand, silt-clay, and species density (ind $\left./ \mathrm{m}^{2}\right)$ in the sampling months (mean $\pm \mathrm{SD})$

\begin{tabular}{lcccc}
\hline Date & March & June & September & November \\
\hline Salinity $(\%)$ & $9.81 \pm 0.17$ & $10.29 \pm 0.71$ & $10.70 \pm 0.3$ & $9.91 \pm 0.32$ \\
Temperature $\left({ }^{\circ} \mathrm{C}\right)$ & $9.68 \pm 0.71$ & $26.35 \pm 3.05$ & $27.36 \pm 1.16$ & $19.03 \pm 0.7$ \\
TOM $(\%)$ & $4.61 \pm 1.119$ & $5.17 \pm 1.25$ & $4.05 \pm 0.59$ & $5.03 \pm 1.22$ \\
Sand $(\%)$ & $87.69 \pm 12.00$ & $93.6 \pm 7.54$ & $92.33 \pm 6.94$ & $95.12 \pm 4.38$ \\
Silt-Clay (\%) & $11.42 \pm 11.43$ & $6.16 \pm 7.61$ & $5.93 \pm 6.08$ & $3.92 \pm 4.45$ \\
Alitta succinea & $3.47 \pm 12.38$ & 0 & $11.81 \pm 26.17$ & $13.89 \pm 23.65$ \\
Hediste diversicolor & $1.39 \pm 6.73$ & 0 & $4.17 \pm 13.09$ & 0 \\
\hline
\end{tabular}

Table 2 Number of individuals found at the different depth lines (line $1=2 \mathrm{~m}$, line $2=5 \mathrm{~m}$, line $3=9 \mathrm{~m}$, and line $4=13 \mathrm{~m}$ depth)

\begin{tabular}{lllll}
\hline Location & March & June & September & November \\
\hline Alitta succinea & & & & \\
Line1 & 0 & 0 & 0 & 4 \\
Line2 & 1 & 0 & 4 & 4 \\
Line3 & 3 & 0 & 6 & 7 \\
Line4 & 1 & 0 & 7 & 5 \\
Hediste diversicolor & & & \\
Line1 & 0 & 0 & 0 & 0 \\
Line2 & 0 & 0 & 0 & 0 \\
Line3 & 0 & 0 & 2 & 0 \\
Line4 & 2 & 0 & 4 & 0 \\
Indet. Nereidid & & & 0 \\
Line1 & 0 & 0 & 0 & 0 \\
Line2 & 0 & 0 & 0 & 0 \\
Line3 & 1 & 0 & 7 & \\
Line4 & 7 & 0 & 9 & \\
\hline
\end{tabular}

rows along the coast line. The mean size of $H$. diversicolor was more than four times higher than that of A. succinea (Table 3).

The specimens fit well with the description and characteristics presented in Fauvel (1923), Kirkegaard (1992) and Bakken and Wilson (2005). A. succinea can be differentiated from $H$. diversicolor mainly in the following morphological aspects:(1) presence of paragnaths on region 5 of the pharynx, (2) larger dorsal notopodial ligules in the posterior parapodium, and (3) lack of fused falcigers which are characteristic of the genus Hediste. In addition, the species differ in life cycle: At sexual maturity, A. succinea undergoes an epitokal metamorphosis to a pelagic heteronereid form. These leave the sediment and swim up to the water surface for mass spawning. $H$. diversicolor lacks an epitokal stage (Kirkegaard 1992). Morphological differences between the species are compiled in Table 3 .

\section{Discussion}

The geographical range of several species has been increased by human activities, both intentionally (e.g. aquaculture) and unintentionally (e.g. interconnection of water basins through canals; shipping activities) (Bij de Vaate et al. 2002). Hediste diversicolor and Alitta succinea have been intentionally introduced to the Aral Sea as food for commercially exploited fish (Proskurina 1980). Both species occur in the Sea of Azov, from which they were taken for introduction to the Caspian Sea. These worms are sufficiently similar that they are unlikely to have been distinguished on sample collection, and most likely, both species were gathered for introduction (Karpinsky et al. 2005). Other evidence suggests that A. succinea was present in the Caspian Sea as early as 1949: Birshtein (1952) reported that the gut contents of the clupeid Alosa saposhnikovi from the north Caspian were dominated by massive number of Nereidids in 1949. Since this fish feeds mainly on pelagic animals (Malkin and Andrianova 2008), it is highly probable that the prey consisted of heteronereids of $A$. succinea, rather than of $H$. diversicolor (Karpinsky et al. 2005). Thus, within several years of introduction to the Caspian Sea, A. succinea was present and reproducing (Belyaev 1952; Navozov-Lavrov 1948).

In our opinion, the species has arrived via intentional introduction. It cannot be excluded that A. succinea had remained undetected before. Due to small population size during the period of arrival and establishment, an early detection of non-indigenous species is difficult. Probably, most introductions in the Caspian Sea were discovered only after populations had reached high abundances (e. g. the bivalves Mytilaster lineatus and Abra ovate) (Grigorovich et al. 2003).

There are several biotic and abiotic factors that may affect the abundance and distribution of the benthic community. Karpinsky (2010) suggested that fish grazing pressure is an important biotic factor influencing the benthic communities in the Caspian Sea. A. succinea and especially its planktonic heteronereid forms are significant prey for a variety of fish including Sturgeon (Karpinsky 2002; Karpinsky et al. 2005), Alosa saposhnikovi (Birshtein 1952), Clupeonella engrauliformis (Stark 1959; Surugiu 2006), Mugil cephalus (Bishop and Miglarese 1978), Neogobius melanostomus and N. cephalarges (Kvach and Zamora 2001). So, abundance and distribution of A. succinea may be controlled by fish predation and thus would 
Table 3 Comparison of characteristics of A. succinea and H. diversicolor in the southern Caspian Sea

\begin{tabular}{lll}
\hline Characteristics & Alitta succinea & Hediste diversicolor \\
\hline Maximal length (mm) & 36 & 91 \\
Mean length \pm SD $(\mathrm{mm})$ & $12.2 \pm 20.3$ & $49.4 \pm 34.4$ \\
Maximal width at chaetiger $10(\mathrm{~mm})$ & 3.8 & 6.1 \\
Mean width \pm SD at chaetiger $10(\mathrm{~mm})$ & $1.7 \pm 2.5$ & $4.9 \pm 3.3$ \\
Maximal no. chaetigers & 76 & 82 \\
Extension of tentacular cirri & To chaetigers 3-8 (rarely 15) & To chaetigers 2-4 \\
No. paragnaths on pharynx region 5 & $0-6$ (usually 2) & Absent \\
No. paragnaths on pharynx region 6 & A big one surrounded by 6-7 smaller ones & $3-9$ \\
Dorsal cirrus & Longer than ligules, inserted distally & Much shorter than ligules \\
Dorsal notopodial ligules of posterior parapodia & Markedly enlarged and elongated & Not markedly enlarged \\
Fused falcigers & Absent & Present \\
Esophagus & Usually everted to ring 1 & Not inverted at all \\
Color & Whitish to yellowish and brownish & Whitish to yellowish and greenish \\
Substrate/sediment type & All sediment types, epi- and infaunal & Soft sediments, infaunal \\
Epitokous stage & Present & Absent \\
\hline
\end{tabular}

increase when predation pressure declines. Reduced predation pressure may have resulted from overexploitation of the fish stock and/or invasion of the ctenophore Mnemiopsis Leidyi and, finally, may be expected to occur wherever fishing nets are deployed. Floating fishing nets are widely used in shallow waters (less than $15 \mathrm{~m}$ depth) from December to June when we found $A$. succinea to be most abundant.

Another possible biological factor affecting the abundance of A. succinea is the ctenophore Mnemiopsis Leidyi, which was also introduced to the Caspian Sea. Roohi et al. (2010) showed that the macrobenthic community shifted from the dominant filter feeding group of crustaceans (Gammaridae) in 1996 to deposit feeding annelids (Hediste diversicolor and oligochaetes) during 2001-2006. Roohi et al. (2010) observed the presence of Nereididae larvae during 2001-2006, which were absent in 1996. So, this ctenophore might have a positive impact on the presence of pelagic Nereidid larvae.

The major structuring abiotic parameter of the Caspian Sea is salinity (Aladin and Plotnikov 2004). The salinity in the surface mixed layer of the sampling area shows annual fluctuations around $10 \%$ (Table 1). The northern, middle, and southern parts of Caspian Sea differ in the salinity of their waters. The average salinities of the middle and southern are 12.7 and $13 \%$, respectively. Reduced values occur only in the deltas of the rivers Sulak, Atrek, Kura, and Sefidrud. The lowest salinity is observed in the northern part of the Caspian Sea. The average salinity of its waters is about 5-10 \%o. However, in certain areas adjacent to the deltas of the rivers Volga, Ural, and Terek, the water salinity is much lower and fluctuates within 2-4\%o, and in the deltas of these rivers, the water can be considered fresh, since its salinity is less than $0.5 \%$ (Aladin and Plotnikov 2004).

Dean and Mazurkiewicz (1975) fertilized eggs of $A$. succinea at $20 \%$ and then exposed them to varying salinities and temperatures. They found normal development of embryos at 10,15 , and $20 \%$, except for the combination of $10 \%$ and $10{ }^{\circ} \mathrm{C}$. Kuhl and Oglesby (1979) suggested survival limits of $A$. succinea at 1 and $80 \%$, while successful fertilization and development can only occur between 10 and $45 \%$. Kristensen (1988) found that the distribution of this worm in a Danish estuary was restricted by salinities lower than $10 \%$. High worm densities were found less than 400 meters away in water of more than $16 \%$. Fong (1991) maintained A. succineaat $5 \%$ for 10-12 months; epitokal metamorphosis took place only after exposure to higher salinities. In contrast, larvae of $H$. diversicolor, from low-salinity Finnish waters (Tvärminne) developed within a salinity range of 5-15\%o (Smith 1964). Larvae from the west coast of Sweden (Kristineberg) where salinity is higher showed optimal development at $19 \%$ and a lower limit of fertilization at about $6 \%$. Belyaev (1952) reported that in the northern Caspian Sea, reproduction of $H$. diversicolor is limited by salinity of lower that $5.6 \%$ and that major colonies of $H$. diversicolor exist at salinities between 5 and $13 \%$. Thus, salinity values may cause limitations to $A$. succinea, especially in the northern Caspian Sea, while $H$. diversicolor may be able to disperse to the regions with salinities lower than $10 \%$. Moreover, $H$. diversicolor may be restricted to the fresher regions of the Caspian Sea by the presence of $A$. succinea.

The water temperature in the Caspian Sea ranges from $0{ }^{\circ} \mathrm{C}$ or less in winter in the northern part, which can be 
partially covered with ice, to $30{ }^{\circ} \mathrm{C}$ in midsummer in the southern Caspian Sea. Both A. succinea and H. diversicolor are apparently able to tolerate the temperature range of the Caspian Sea. Both species survive and reproduce successfully in the Sea of Azov at winter water temperatures as low as $0{ }^{\circ} \mathrm{C}$ similar to the northern Caspian Sea (Stark 1959). Kuhl and Oglesby (1979) have shown that temperatures as high as $34{ }^{\circ} \mathrm{C}$ do not have any marked effect on adult survival and reproduction of $A$. succinea. However, higher temperature may have a synchronizing effect on epitokal metamorphosis in A. succinea (Fong 1991).

In the sampling area, A. succinea was collected at all depths in both soft and rocky substrates, while $H$. diversicolor was collected only along lines 3 and 4 in March and September, in an habitat characterized relatively greater depth and higher TOM and silt-clay. In the Gorgan Bay, which is characterized by soft silty substrate, only $H$. diversicolor is recorded (Taheri et al. 2011, 2012). Stygar and Mutysheva (2000) reported locally high abundances of $H$. diversicolor in the Uralsk Trench in the eastern part of north Caspian Sea, which has a greater depth and a higher percentage of silt-clay. For the Isefjord, Rasmussen (1973) suggested that the locally abundant $A$. succinea is a predator which mainly preys on quite large prey, like $H$. diversicolor. As $H$. diversicolor seems to be rare where $A$. succinea is common (Smith 1963), H. diversicolor may be restricted mainly to the soft bottoms at greater depth by the presence of A. succinea.

Although the establishment of this Nereidid as an additional food source could facilitate the recreation of commercially exploited fish stocks, the consequences for native benthic communities remain unclear and might be subject to unforeseen negative impacts. So, further studies are required to monitor potential impacts of A. succinea on the benthic communities in the Caspian Sea.

Acknowledgments The author gratefully acknowledges the valuable comments and advices of Dr. Mikhail G. Karpinsky, and thanks Dr. Torkild Bakken for his help in the identification of specimens. Special thank is due to Tina Fartash Benmar and Rozhin Asghari Moghaddam who checked and improved the English.

\section{References}

Abrantes A, Pinto F, Moreira MH (1999) Ecology of the polychaete Nereis diversicolor in the canal de mira (Ria de AveiroPortugal): population dynamics, production and oogenic cycle. Acta Oecol 20(4):267-283

Aladin NV, Plotnikov IS (2004) The Caspian Sea. Lake basin management initiative. Thematic paper, Moscow

Bakken T, Wilson RS (2005) Phylogeny of Nereidids (Polychaeta, Nereididae) with paragnaths. Zool Scr 34:507-547

Belyaev GM (1952) The biology of Nereis succinea in the North Caspian Sea. In: Nikitin VN (ed) Acclimatization of Nereis in the Caspian Sea. MOIP, Moscow 33:243-284 (in Russian)
Bij de Vaate A, Jazdzewski K, Ketelaars HAM, Gollasch S, Van der Velde G (2002) Geographical patterns in range extension of ponto-Caspian macroinvertebrate species in Europe. Can J Fish Aquat Sci 59:1159-1174

Birshtein YaA (1952) The feeding of the benthophagous fishes of the Caspian Sea (except sturgeons) in 1948-1949 and their consumption of Nereis succinea. In: Nikitin VN (ed) Acclimatization of Nereis in the Caspian Sea. MOIP, Moscow 33:115-144 (in Russian)

Bishop JM, Miglarese JV (1978) Carnivorous feeding in adult striped mullet. Copeia 4:705-707

Dean D, Mazurkiewicz M (1975) Methods of culturing polychaetes. In: Smith W, Matoira HC (eds) Culture of marine invertebrate animals. Plenum Press, New York, pp 177-197

Fauvel P (1923) Faune de France. vol 5: polychètes errantes. Paul Lechevalier, Paris

Fong PP (1991) The effects of salinity, temperature, and photoperiod on epitokal metamorphosis in Neanthes succinea (Frey et Leuckart) from San Francisco Bay. J Exp Mar Biol Ecol 149:177-190

Grigorovich IA, Therriault TW, MacIsaac HJ (2003) History of aquatic invertebrate invasions in the Caspian Sea. Biol Invasions 5:103-115

Guseinov MK (2005) Zoobenthic communities of the Dagestan region of the Caspian Sea. Russ J Mar Biol 31(1):7-13

Hadjizadeh Zaker N, Ghafari P, Jamshidi S (2007) Physical study of the southern coastal waters of the Caspian Sea, off Babolsar, Mazandaran in Iran. J Coast Res 50:564-569

Hartman O (1960) An account of the nereid worms, Neanthes diversicolor, a new combination in the Caspian Sea and its more extensive distribution. Zool J 39:35-39 (in Russian)

Karpevich AF (1968) Results and prospects of work on acclimatization of fish and invertebrates in the southern seas of the USSR. In: Karpevich AF (ed) Acclimatization of fish and invertebrates in the water bodies of the USSR. Nauka, Moscow, pp 50-67

Karpevich AF (1975) Theory and practice of acclimatization of aquatic organisms. Pishchevaya Promyshlennost, Moscow (in Russian)

Karpinsky MG (2002) Ecology of the benthos of the Middle and Southern Caspian. VNIRO, Moscow (in Russian)

Karpinsky MG (2010) Review: the Caspian Sea benthos: unique fauna and community formed under strong grazing pressure. Mar Pollut Bull 61:156-161

Karpinsky MG, Shiganova TA, Katunin DN (2005) Introduced species. In: Kostianoy AG, Kosarev AN (eds) The handbook of environmental chemistry: the Caspian Sea environment, vol 5. Springer, Berlin, pp 175-190

Khlebovich VV (1963) On the systematic position of the nereid from the Caspian Sea. Zool J 42:129-131 (in Russian)

Kirkegaard JB (1992) Havbarsteorme I. Errantia. Danmarks Fauna. Dansk Naturhistorisk Forening, zoological museum, Copenhagen

Kristensen E (1988) Factors influencing the distribution of nereid polychaetes in Danish coastal waters. Ophelia 29:127-140

Kuhl DL, Oglesby LC (1979) Reproduction and survival of the pileworm Nereis succinea in higher Salton Sea salinities. Biol Bull 157:153-165

Kvach Y, Zamora V (2001) Feeding preferences of the round goby Neogobius melanostomus and mushroom goby Neogobius cephalarges in the Odessa Bay. Oceanol Study 30(3-4):91-101

Malinovskaja LV, Filippov AA, Osadchikh VF, Aladin NV (1998) Benthic macroinvertebrates of the northern Caspian Sea during recent rises in water-level. Int J Salt Lake Res 7:211-233

Malkin EM, Andrianova SB (2008) Biology and traits of the formation of stock of big-eyed shad Alosa Saposchnikowii. J Ichthyol 48(6):443-451

Navozov-Lavrov NP (1948) Azov Nereids in the Middle Caspian. Rybnoe khozyajstvo 9:40 (in Russian) 
Proskurina YS (1980) The state of introduced species in the Aral Sea and the prospects for their spread. Hydrobiol J 15:30-34 (English version)

Rasmussen E (1973) Systematics and ecology of the Isefjord marine fauna (Denmark). Ophelia 11:1-507

Roohi A, Kideys AE, Sajjadi A et al (2010) Changes in biodiversity of phytoplankton, zooplankton, fishes and macrobenthos in the Southern Caspian Sea after the invasion of the ctenophore Mnemiopsis leidyi. Biol Invasions 12:2343-2361

Shafiei Sabet B, Barani GA (2011) Field investigation of rip currents along the southern coast of the Caspian Sea. Sci Iran 18(4):878-884

Smith RI (1963) On the occurrence of Nereis (Neanthes) succinea at the Kristineberg Zoological Station, Sweden, and its recent northwards spread. Arkiv för Zool 15:437-441

Smith RI (1964) On the early development of Nereisdiversicolor in different salinities. J Morphol 114:437-464

Spassky NN (1945) The finding of an annelid worm in the waters of the North Caspian Sea. Zool J 24(1):23-24 (in Russian)

Stark IN (1959) Nereis succinea in the Sea of Azov. Zool J 38(11):1634-1648 (in Russian)
Stygar VM, Mutysheva GK (2000) Zoobenthos of the eastern part of the North Caspian Sea in the zone of proposed development of hydrocarbon material deposits in the period of sea level stabilization. Marine Hydrobiological Research. VNIRO, Moscow, pp 111-126

Surugiu V (2006) Preliminary study concerning the role of the benthic polychaetes in the feeding of some fish species from Romanian coast of the Black Sea. Acta Ichtiol Rom 1:281-292

Taheri M, Foshtomi M (2010) Community structure and biodiversity of shallow water macrobenthic fauna at Noor coast, South Caspian Sea, Iran. J Mar Biol Assoc UK 90(5):1-7

Taheri M, Foshtomi M, Noranian M, Mira SS (2011) Annelida community structure in the Gorgan Bay, Southeast of Caspian Sea, Iran-acase study. World J Fish Mar Sci 3(5):414-421

Taheri M, Foshtomi M, Noranian M, Mira SS (2012) Spatial distribution and biodiversity of macrofauna in the southeast of the Caspian Sea, Gorgan Bay in relation to environmental conditions. Ocean Sci J 47(2):113-122

Zenkevitch LA, YaA Birshtein, Karpevich AF (1945) The first successes of the systematic reconstruction of the Caspian Sea fauna. Zool J 24(1):25-31 (in Russian) 